\title{
1,4-Dioxane Biodegradation by Mycobacterium dioxanotrophicus PH- 06 Is Associated with a Group-6 Soluble Di-Iron Monooxygenase
}

\author{
Ya He, ${ }^{\dagger}$ Jacques Mathieu, ${ }^{\dagger}$ Yu Yang, ${ }^{\dagger}$ Pingfeng Yu, ${ }^{\dagger}{ }^{\circ}$ Marcio L. B. da Silva, ${ }^{\dagger}$ and Pedro J. J. Alvarez ${ }^{* \dagger}{ }^{\dagger}$
}

${ }^{\dagger}$ Department of Civil and Environmental Engineering, Rice University, Houston, Texas 77005, United States

Supporting Information

\begin{abstract}
Dioxane (dioxane) is a groundwater contaminant of emerging concern for which bioremediation may be a promising strategy. Several bacterial strains can metabolize dioxane or degrade it cometabolically. However, the molecular basis of dioxane biodegradation is only partially understood, and the gene coding for dioxane/ tetrahydrofuran (THF) monooxygenase in Pseudonocardia dioxanivorans CB1190 is the only well-characterized catabolic gene. Here, we identify a novel group-6 propane monooxygenase gene cluster (prmABCD) in Mycobacterium dioxanotrophicus PH-06, which is a bacterium with superior dioxane degradation kinetics compared with CB1190. Whole genome sequencing of $\mathrm{PH}-06$ revealed the existence of a single soluble di-iron monooxygenase (SDIMO). RNA sequencing and reverse transcription quantitative PCR (RT-qPCR)
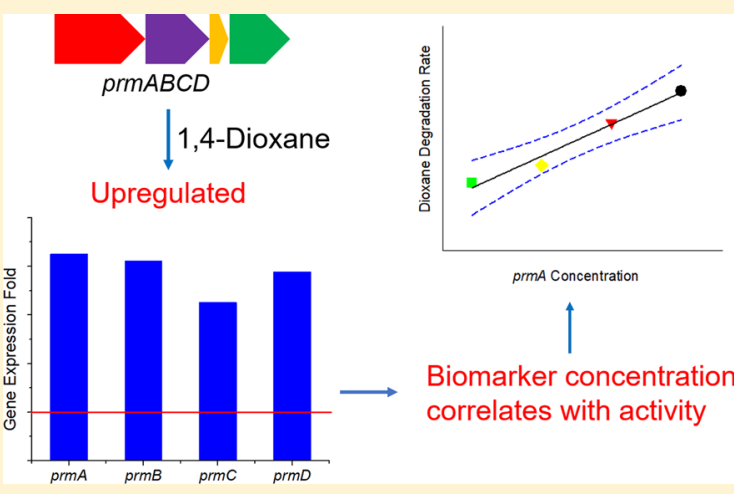

Biomarker concentration correlates with activity subsequently confirmed that all four components of this gene cluster are upregulated when $\mathrm{PH}-06$ is grown on dioxane compared with growth on acetate or glucose as negative controls. This first characterization of a group-6 SDIMO associated with dioxane biodegradation suggests that dioxane-degrading genes may be more diverse than previously appreciated. A primer/probe set designed to target the large hydroxylase subunit of this gene cluster exhibited high selectivity (no false positives) and high sensitivity (detection limit $=3000-4000$ gene copies $/ \mathrm{mL}$ culture), which may be useful to help assess the presence of dioxane degraders at contaminated sites and minimize false negatives.
\end{abstract}

\section{INTRODUCTION}

1,4-Dioxane (dioxane) is a groundwater contaminant of emerging concern that is classified as a probable human carcinogen (Class B2) by the U.S. Environmental Protection Agency. ${ }^{1,2}$ Dioxane was widely used as a stabilizer for chlorinated solvents and is commonly found as a cocontaminant at thousands of solvent-impacted sites. ${ }^{3}$ Removal of dioxane from such sites is usually challenging due to its relative recalcitrance to biodegradation and high migration potential. ${ }^{1}$ Several pure strains or consortia capable of degrading dioxane have been isolated, ${ }^{4-13}$ which suggests that bioremedation and monitored natural attenuation may be a promising strategy to manage dioxane contamination at some sites. When applicable, such biodegradation approaches (including intrinsic bioremediation associated with monitored natural attenuation [MNA]) are usually more economical and environmentally friendly than more aggressive remediation alternatives such as advanced oxidation, especially for managing large and dilute dioxane plumes. ${ }^{3}$ However, the burden of proof that MNA is an appropriate solution lies on the proponent. Thus, there is a growing need for molecular tools to quantitatively assess the presence and activity of dioxane degraders to support decisions to accept or reject MNA. This could result in significant economic benefits associated with overcoming the current underutilization of MNA and advance understanding of the diversity of the associated degradation pathways.

Soluble di-iron monooxygenases (SDIMOs) play a key role in dioxane biodegradation. ${ }^{14,15}$ Based on the number and arrangement of subunits, substrate specificity, and sequence similarity, SDIMOs are categorized into six groups. ${ }^{16,17}$ Recent genomic and molecular studies with Pseudonocardia dioxanivorans CB1190 helped elucidate the role of the group-5 SDIMO gene cluster thm $A D B C$ (located on a plasmid), which codes for a monooxygenase associated with the initial hydroxylation of dioxane at the $\alpha$ carbon position, leading to the cleavage of the high-energy $\mathrm{C}-\mathrm{O}$ bond. ${ }^{4,18-20}$ Gene clusters with high sequence similarities have been identified in bacteria capable of degrading tetrahydrofuran (THF), which is a structural analog of dioxane. ${ }^{21-23}$ In addition, group-5 SDIMO genes were enriched at a number of geographically distinct, dioxaneimpacted sites. ${ }^{24}$ However, little is known about the importance of other SDIMO groups dioxane bioremediation.

We recently observed an increase in group-6 SDIMO genes in two dioxane-degrading consortia enriched from soil samples. These consortia are dominated by Mycobacterium spp. and do

Received: October 10, 2017

Revised: October 31, 2017

Accepted: October 31, 2017

Published: October 31, 2017 
not harbor thm $A D B C,{ }^{10}$ indicating that probing for this gene would give false negatives regarding dioxane degradation potential. Moreover, dioxane-degrading isolate Mycobacterium dioxanotrophicus $\mathrm{PH}-06$ lacks thm $A D B C$, which was confirmed by PCR, qPCR (data not shown), and whole genome sequencing. ${ }^{5,25,26}$ PH-06 exhibits higher affinity for dioxane $(\mathrm{Ks}=78 \pm 10 \mathrm{mg} / \mathrm{L})$ and greater cell yield $(\mathrm{Y}=0.16 \mathrm{~g}$ protein/g dioxane) than the archtype dioxane degrader CB1190 (Ks $=145 \pm 17 \mathrm{mg} / \mathrm{L}, \mathrm{Y}=0.11 \mathrm{~g}$ protein $/ \mathrm{g}$ dioxane (Figure S1), which suggests that it could be a more suitable candidate for bioaugmentation. Since bioaugmentation involves not only inoculation but also monitoring, primers and probes are needed to quantify appropriate genes from recovered field samples.

Here, we identify and characterize a novel plasmid-encoded group-6 SDIMO gene cluster responsible for dioxane degradation by $\mathrm{PH}-06$, which is phylogenetically disparate from other well-studied dioxane degraders. A primer/probe set was also designed to target the hydroxylase subunit of this gene cluster, which will enhance the assessment of the biodegradation potential at dioxane-impacted sites.

\section{MATERIALS AND METHODS}

2.1. Bacterial Strains and Culture Conditions. Mycobacterium dioxanotrophicus $\mathrm{PH}-06^{5,26}$ was provided by Dr. Yoon-Seok Chang (POSTECH, South Korean). PH-06 was grown in an ammonium mineral salts (AMS) medium. ${ }^{4,27}$ Growth substrates (dioxane, THF, glucose, or sodium acetate) were added to the culture medium to achieve a final concentration of $500 \mathrm{mg} / \mathrm{L}$. Glucose and acetate are used as control substrates for transcriptomic studies because they are readily biodegradable without the need for SDIMOs. Although dioxane concentrations at contaminated sites are commonly lower than $1 \mathrm{mg} / \mathrm{L},{ }^{3}$ these relatively high concentrations were used to easily observe growth and obtain sufficient biomass for transcriptomic and other analyses. Nevertheless, PH-06 and the other tested consortia can degrade dioxane even when present below $300 \mu \mathrm{g} / \mathrm{L} .{ }^{10}$ Other strains used for primer/probe tests (Table S1) were grown in an AMS medium with $500 \mathrm{mg} / \mathrm{L} \mathrm{1-}$ propanol. All cultures were incubated aerobically, while shaking at $150 \mathrm{rpm}$ at $30^{\circ} \mathrm{C}$.

2.2. RNA Sequencing. RNA sequencing was used to investigate gene expression levels of $\mathrm{PH}-06$ during growth on two different carbon sources (dioxane and glucose). RNA was extracted from PH-06 cells grown in dioxane or glucose as described in the Supporting Information. RNA samples were sent to an external sequencing facility (LC Sciences, Houston, TX, USA) for mRNA sequencing. Total RNA quality control was performed with a NanoDrop ND-1000 apectrophotometer (NanoDrop Products Inc., ThermoFisher Scientific, Waltham, MA, USA) and an Agilent 2100 bioanalyzer (Agilent Technologies, Santa Clara, CA, USA) to make sure both UV absorbance parameters $\mathrm{A}_{260} / \mathrm{A}_{230}$ and $\mathrm{A}_{260} / \mathrm{A}_{280}$ were 1.8-2.2, and the RNA integrity number (RIN) was larger than 8 . Then, mRNA libraries were prepared with the Illumina mRNA-Seq sample prep kit, and sequencing was performed using an Illumina HiSeq 2500 system with a single-end (SE) rapid-run mode. Raw reads were mapped to the whole genome sequencing of $\mathrm{PH}-06,{ }^{26}$ and the relative gene expression levels were estimated using EDGE-pro v 1.3.1 (http://ccb.jhu.edu/ software/EDGE-pro/). ${ }^{28-30}$ These sequence data were submitted to the GenBank database under accession number SRP116048.
2.3. Reverse Transcription Quantitative PCR (RTqPCR). Total RNA was extracted from PH-06 cells after growth on dioxane, THF, glucose, and sodium acetate. The cDNA was synthesized using high-capacity cDNA reverse transcription kits with the addition of an RNase inhibitor (Applied Biosystems, Foster City, CA, USA). The synthesized cDNA was purified with Wizard SV gel and the PCR clean-up system (Promega, Madison, WI, USA) following the manufacturer's protocol. The cDNA concentration in the elution $(30 \mu \mathrm{L})$ was determined by NanoDrop ND-1000 and subsequently diluted to $10 \mathrm{ng} / \mu \mathrm{L}$ with nuclease-free water for RT-qPCR analysis. The RT-qPCR mixture contained $1 \mu \mathrm{L}$ of diluted cDNA $(10 \mathrm{ng} / \mu \mathrm{L}), 7.5 \mu \mathrm{L}$ of $2 \mathrm{X}$ SYBR green PCR master mix (Applied Biosystems, Foster City, CA, USA), 0.3 $\mu \mathrm{M}$ of each forward and reverse primers, and DNA-free water to a total volume of $15 \mu \mathrm{L}$. RT-qPCR was performed in a CFX 96 real-time system (Bio-Rad, Hercules, CA, USA) with the following temperature set up: $95{ }^{\circ} \mathrm{C}$ for $10 \mathrm{~min}$ and 40 cycles of $95^{\circ} \mathrm{C}$ for $15 \mathrm{~s}$ and $60^{\circ} \mathrm{C}$ for $1 \mathrm{~min}$. Specific primers (Table S2) targeting each subunit of the monooxygenase gene cluster were designed by the Primer Quest Tool (Integrated DNA Technologies, Coralville, IA, USA). Differential gene expression was quantified by the $2^{-\Delta \Delta C_{T}}$ method $^{31}$ (Supporting Information) using the $16 \mathrm{~S}$ rRNA gene of $\mathrm{PH}-06$ as the reference gene. Treatments with glucose or sodium acetate as the sole carbon source were used as controls to calculate the expression level of the target genes in the presence of dioxane or THF.

2.4. Design and Evaluation of prmA Primer/Probe Set. A primer/probe set targeting the hydroxylase subunit ( $p r m A)$ was designed to evaluate the dioxane bioremediation potential. Quantitative PCR (qPCR) by TaqMan assays was conducted on the genomic DNA (including chromosomal and plasmid DNA) extracted from reference strains (Table S1) or from enriched cultures (Table S3) to testify the effectiveness of this primer/probe set. The PCR mixture contained $1 \mu \mathrm{L}$ of $1 \mathrm{ng} / \mu \mathrm{L}$ DNA (or a series of diluted DNA), $300 \mathrm{nM}$ of forward and reverse primers, a $150 \mathrm{nM}$ probe, $10 \mu \mathrm{L}$ of TaqMan universal master mix II (Applied Biosystems, Foster City, CA), and DNA-free water to a total volume of $20 \mu \mathrm{L}$. qPCR was performed in a CFX 96 real-time system (Bio-Rad, Hercules, CA, USA) with the following temperature set up: $50{ }^{\circ} \mathrm{C}$ for 2 min, $95{ }^{\circ} \mathrm{C}$ for $10 \mathrm{~min}$, and 40 cycles of $95{ }^{\circ} \mathrm{C}$ for $15 \mathrm{~s}$ and 60 ${ }^{\circ} \mathrm{C}$ for $1 \mathrm{~min}$. Serial dilutions of extracted genomic DNA of PH06 were utilized to prepare the calibration curves for prmA and $16 \mathrm{~S}$ rRNA.

2.5. Analytical Procedures. Biomass was quantified through total protein concentration using a Pierce BCA protein assay kit (Thermo Fisher Scientific, Rockford, IL, USA). Dioxane and THF were measured using an Agilent 7820A gas chromatograph (GC) equipped with a 5977E mass spectrum detector (MSD) after filtration through $0.22 \mu \mathrm{m} 13 \mathrm{~mm}$ syringe filters and extraction by a liquid/liquid frozen microextraction method using dichloromethane as the solvent. ${ }^{32}$ Glucose and sodium acetate concentrations were determined by an Agilent 5890 gas chromatograph (GC) with a flame ionization detector (FID) after derivation. ${ }^{33,34}$

2.6. Statistical Analysis. All treatments were conducted in triplicate. Statistical significance of differences between experimental treatments was assessed using the two-tailed unpaired Student's $t$-test at the $95 \%$ confidence level. 


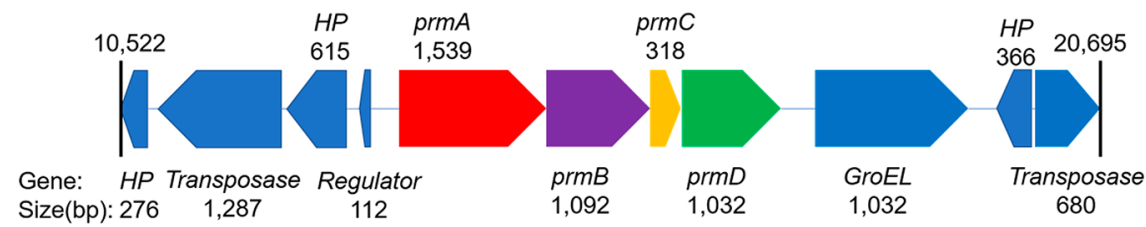

Figure 1. Scheme of the propane monooxygenase (prmABCD) gene cluster. The numbers on the above left and right sides indicate their locations in Plasmid_3. The arrows indicate genes, and the strings between them indicate the gaps between different genes. The lengths of the strings and the arrows are proportional to their relative sizes. The right or left direction of the arrows indicates a positive or negative strand. Gene name abbreviation: HP (hypothetical protein), Regulator (two-component system response regulator), prmA (propane monooxygenase alpha subunit), prmB (propane monooxygenase beta subunit), prmC (propane monooxygenase coupling protein), prmD (propane monooxygenase reductase protein), and GroEL (chaperonin GroEL).
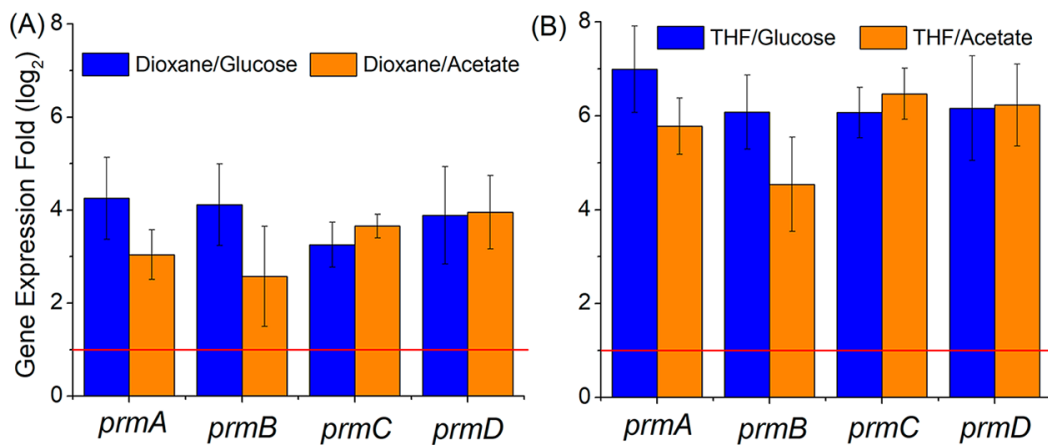

Figure 2. Upregulation of prmABCD in $\mathrm{PH}-06$ pure cultures grown on dioxane (A) and THF (B) relative to glucose or acetate. The $16 \mathrm{~S}$ rRNA gene of $\mathrm{PH}-06$ was used as the housekeeping gene for error control among samples. The red horizontal lines indicate significant upregulation criteria (2fold gene expression change).
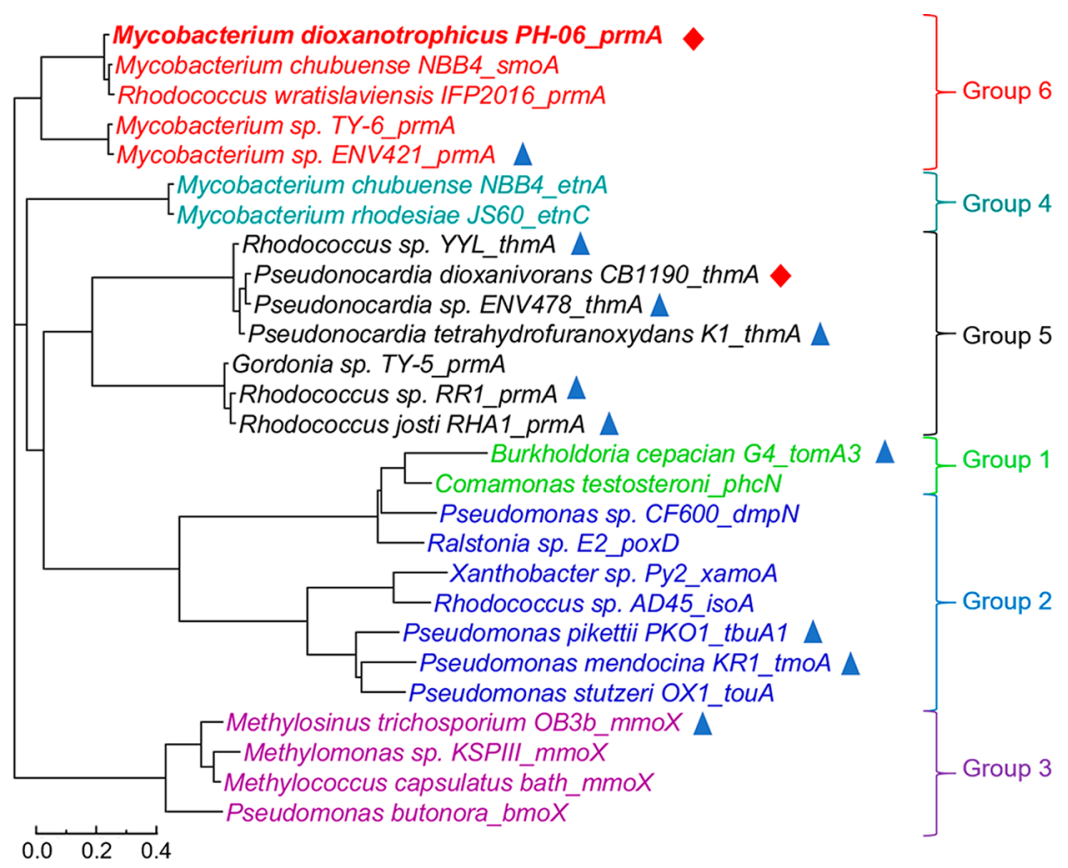

Figure 3. Neighbor-joining tree showing the phylogenetic relationship of the large hydroxylase subunit of prmABCD with other SDIMOs. The tree was generated on TreeGraph2 based on the alignment of amino acid sequences. Only the strains marked with a red diamond or a blue triangle are confirmed to degrade dioxane metabolically or cometabolically, respectively. The scale bar indicates the average number of amino acid substitutions per site. Group numbers to which these SDIMOs belong to are indicated on the right.

\section{RESULTS AND DISCUSSION}

3.1. Whole Genome Sequencing Identified One SDIMO Gene Cluster in PH-06. Dioxane degradation by $\mathrm{PH}-06$ is likely initiated by a monooxygenase, as suggested by a previous isotope labeling study ${ }^{5}$ and supported by our acetylene inhibition test (Figure S2), which is a common approach to determine the participation of monooxygenases. ${ }^{35}$ The PH-06 genome contains only one SDIMO gene cluster (Figure 1) located in Plasmid_3. ${ }^{26}$ Because another SDIMO has been reported to play a key role in dioxane biodegradation by CB1 190, ${ }^{14,15}$ we expolored its association with dioxane degradation by PH-06. This SDIMO gene cluster has four 

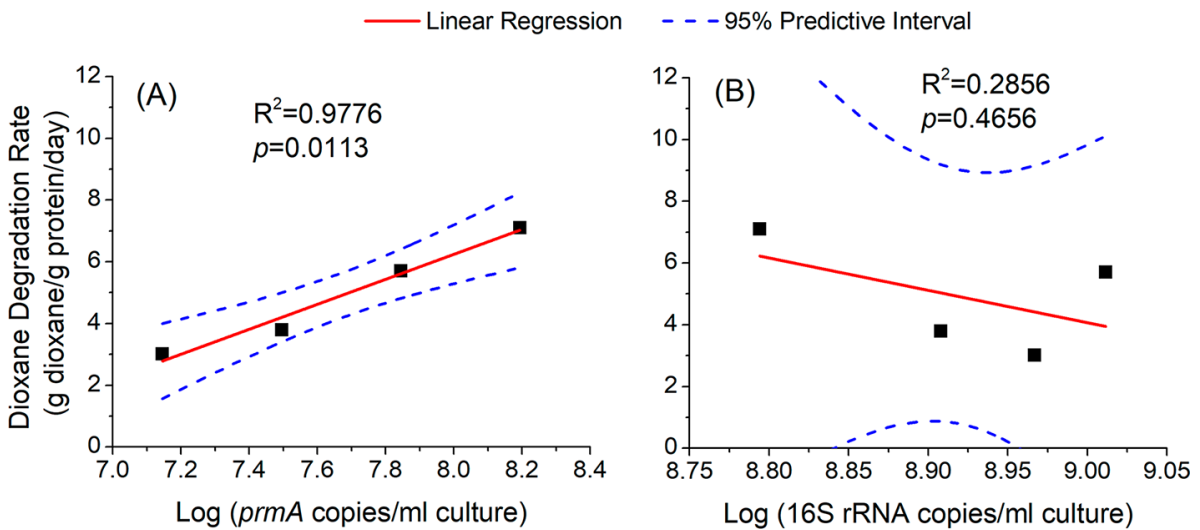

Figure 4. Correlation between dioxane degradation rate and abundance of prmA (A) but not 16S rRNA (B) gene copies. Experiments were conducted with microbial consortia enriched from soil or activated sludge (Table S3).

subunits (a hydroxylase with large and small subunits, a coupling protein, and a reductase) with a total size of approximately $4 \mathrm{~kb}$ (Figure 1). NCBI BLAST results show that this gene cluster has high similarity with propane monooxygenase genes of Rhodococcus wratislaviensis IFP 2016 (89\%), Mycobacterium chubuense NBB4 (86\%), and Mycobacterium spp. ENV421 (89\%). ${ }^{36-38}$ Thus, we named this SDIMO gene cluster as propane monooxygenase prm $A B C D$. Upregulation of this gene cluster by propane was verified (Figure S3).The presence of a transposase gene immediately upstream or downstream of prmABCD (Figure 1), and its lower $\mathrm{G}+\mathrm{C}$ content $(62.9 \%)$ compared with the chromosome $(66.5 \%){ }^{26}$ suggest that it may have originated from horizontal gene transfer.

3.2. RNA-seq and RT-qPCR Demonstrated Upregulation of prmABCD by Dioxane. To determine whether prm $A B C D$ is involved in dioxane degradation, RNA sequencing (RNA-seq) was used to quantify gene expression levels during growth on dioxane or glucose. Relative to glucose, dioxane significantly upregulated prmABCD. The expression foldchanges were $6.5,8.1,9.7$, and 10.7 for the four subunits, respectively (Table S4). Another multicomponent monooxygenase gene cluster (i.e., ammonia monooxygenase) located in Plasmid_3 and several different monooxygenase genes located in the chromosome were also upregulated (Table S4). However, the functions of these encoded enzymes exclude their involvement in dioxane degradation. For example, ammonia monooxygenase catalyzes the oxidation of ammonia to hydroxylamine, ${ }^{39}$ while cyclohexanone monooxygenase catalyzes an oxygen insertion on cyclohexanone to form a cyclic lactone. ${ }^{40}$ Therefore, prmABCD was chosen for further studies and confirmation of its involvement in dioxane degradation.

RT-qPCR experiments confirmed upregulation of the four subunits when treated with dioxane or its analog THF in comparison with glucose and acetate (Figure 2). Additionally, THF induced higher expression of prmABCD (1.5-2 times) compared with dioxane (Figure 2), which is consistent with the preferential consumption of THF when THF and dioxane were fed concurrently (Figure S4). This preferential utilization was also corroborated by an aquifer microcosm study. ${ }^{41}$

3.3. prmABCD Is the First Identified Group-6 SDIMO Associated with Dioxane Degradation. According to the classification rules of SDIMOs, which are based on the number and arrangement of subunits, substrate specificity, and sequence similarity, ${ }^{16,17}$ prmABCD is a group-6 SDIMO. The amino acid sequence alignment of the large hydroxylase subunit ( prmA) with other SDIMOs shows that this gene cluster is significantly different and phylogenetically distant from the th $m A D B C$ gene cluster (Figure 3). This explains the absence of the thmA/dxmA biomarker $^{25}$ in Mycobacterium dioxanotrophicus PH-06 by qPCR (data not shown). Though another Mycobacterium (i.e., ENV421) also harbors a group-6 SDIMO (Figure 3), the association of this SDIMO with dioxane degradation was not confirmed by heterologous host gene studies. ${ }^{38}$ To our best knowledge, prmABCD is the only identified group-6 SDIMO associated with dioxane degradation in a pure bacterial strain. This suggests that dioxane-degrading genes are more diverse than previously appreciated, and it provides a basis for minimizing false negatives when looking for them at contaminated sites.

3.4. The prmA Primer/Probe Set Is Selective, and Its Abundance Is Significantly Correlated with Degradation Activity of Enriched Consortia. To facilitate the assessment of the dioxane degradation potential at impacted sites, a primer/probe set targeting the hydroxylase subunit ( $p r m A$ ) was designed based on the following criteria: (1) Avoid di-iron centers (i.e., DE*RH motif) conserved by all SDIMOs because they are the active sites for hydroxylation or peroxidation reactions. (2) Target the surrounding hydrophobic residues because they may be associated with the substrate recognition and binding. ${ }^{16,42}$ The amino acid residues selected for this biomarker design are marked in Figure S5, and the corresponding DNA sequences were used to generate the primer/probe set (Table S5). This primer/probe set exhibited high sensitivity (detection limit $=3000-4000$ gene copies $/ \mathrm{mL}$ culture, which is within the commonly reported range for catabolic genes (Table S6)) and no false positives, even with other oxygenase genes that bear a close evolutionary relationship (Table S1).

The performance of our primer/probe set was also tested with four dioxane-degrading consortia (Table S3) where Mycobacterium spp. were dominant ${ }^{10}$ (Figure S6). The specific degradation rates of these consortia were significantly correlated $(p<0.05)$ with the abundance of this prmA biomarker (indicative of the concentration of specific degraders harboring group-6 SDIMO genes) but not with 16S rRNA (indicative of total bacteria concentration) (Figure 4). Although caution should be exercised about correlations based on only four data points obtained with relatively high dioxane 
concentrations, the depicted $95 \%$ predictive intervals clearly suggest that this prmA biomarker (but not $16 \mathrm{~S}$ rRNA) can be a valuable indicator of potential dioxane degradation activity. A sample from aquifer material (Table S3) impacted by dioxane but not exhibiting biodegradation activity was included as the negative control; consistently, the prmA biomarker was not detected (i.e., no false positive) (Supporting Information) (detection limit $=6000-7000$ gene copies $/ \mathrm{mL}$ aquifer).

While the abundance of the group-5 SDIMO thmA/dxmA biomarker can also be positively correlated with dioxane biodegradation at some sites, ${ }^{25}$ this analysis may suffer from false negatives if the predominant dioxane degraders are Mycobacterium species, which we have found may be more widespread than previously appreciated. ${ }^{10}$ Thus, the new prmA biomarker would help reduce the occurrence of false negatives when assessing dioxane natural attenuation.

\section{ASSOCIATED CONTENT}

\section{(S Supporting Information}

The Supporting Information is available free of charge on the ACS Publications website at DOI: 10.1021/acs.estlett.7b00456.

Additional methods and results, Figure S1-S6, and Table S1-S6. (PDF)

\section{AUTHOR INFORMATION}

\section{Corresponding Author}

*Pedro J. J. Alvarez. E-mail: alvarez@rice.edu. Phone: +17133485903. Fax: +1-7133485268.

ORCID

Pingfeng Yu: 0000-0003-0402-773X

Pedro J. J. Alvarez: 0000-0002-6725-7199

Notes

The authors declare no competing financial interest.

\section{ACKNOWLEDGMENTS}

This work was funded by SERDP (Grant No. ER-2301).

\section{REFERENCES}

(1) Zenker, M. J.; Borden, R. C.; Barlaz, M. A. Occurrence and treatment of 1,4-dioxane in aqueous environments. Environ. Eng. Sci. 2003, 20, 423-432.

(2) 1,4-Dioxane; Technical Fact Sheet EPA 505-F-14-011; U.S. EPA, 2014

(3) Adamson, D. T.; Mahendra, S.; Walker, K. L., Jr; Rauch, S. R.; Sengupta, S.; Newell, C. J. A multisite survey to identify the scale of the 1,4-dioxane problem at contaminated groundwater sites. Environ. Sci. Technol. Lett. 2014, 1, 254-258.

(4) Parales, R. E.; Adamus, J. E.; White, N.; May, H. D. Degradation of 1,4-dioxane by an actinomycete in pure culture. Appl. Environ. Microbiol. 1994, 60, 4527-4530.

(5) Kim, Y.-M.; Jeon, J.-R.; Murugesan, K.; Kim, E.-J.; Chang, Y.-S. Biodegradation of 1,4-dioxane and transformation of related cyclic compounds by a newly isolated Mycobacterium sp. PH-06. Biodegradation 2009, 20, 511-519.

(6) Sei, K.; Miyagaki, K.; Kakinoki, T.; Fukugasako, K.; Inoue, D.; Ike, M. Isolation and characterization of bacterial strains that have high ability to degrade 1,4-dioxane as a sole carbon and energy source. Biodegradation 2013, 24, 665-674.

(7) Lippincott, D.; Streger, S. H.; Schaefer, C. E.; Hinkle, J.; Stormo, J.; Steffan, R. J. Bioaugmentation and propane biosparging for in situ biodegradation of 1,4-dioxane. Groundwater Monit. Remediat. 2015, 35, 81-92.
(8) Pugazhendi, A.; Banu, J. R.; Dhavamani, J.; Yeom, I. T. Biodegradation of 1,4-dioxane by Rhodanobacter AYS5 and the role of additional substrates. Ann. Microbiol. 2015, 65, 2201-2208.

(9) Chen, D.-Z.; Jin, X.-J.; Chen, J.; Ye, J.-X.; Jiang, N.-X.; Chen, J.-M. Intermediates and substrate interaction of 1,4-dioxane degradation by the effective metabolizer Xanthobacter flavus DT8. Int. Biodeterior. Biodegrad. 2016, 106, 133-140.

(10) He, Y.; Mathieu, J.; da Silva, M. L. B. d.; Li, M.; Alvarez, P. J. 1,4Dioxane degrading consortia can be enriched from uncontaminated soils: Prevalence of Mycobacterium and soluble di-iron monooxygenase genes. Microb. Biotechnol. 2017, na.

(11) Isaka, K.; Udagawa, M.; Kimura, Y.; Sei, K.; Ike, M. Biological wastewater treatment of 1,4-dioxane using polyethylene glycol gel carriers entrapping Afipia sp. D1. J. Biosci. Bioeng. 2016, 121, 203-208.

(12) Inoue, D.; Tsunoda, T.; Sawada, K.; Yamamoto, N.; Saito, Y.; Sei, K.; Ike, M. 1,4-Dioxane degradation potential of members of the genera Pseudonocardia and Rhodococcus. Biodegradation 2016, $27,277$.

(13) Hand, S.; Wang, B.; Chu, K.-H. Biodegradation of 1, 4-dioxane: effects of enzyme inducers and trichloroethylene. Sci. Total Environ. 2015, 520, 154-159.

(14) Mahendra, S.; Alvarez-Cohen, L. Kinetics of 1,4-dioxane biodegradation by monooxygenase-expressing bacteria. Environ. Sci. Technol. 2006, 40, 5435-5442.

(15) Mahendra, S.; Petzold, C. J.; Baidoo, E. E.; Keasling, J. D.; Alvarez-Cohen, L. Identification of the intermediates of in vivo oxidation of 1,4-dioxane by monooxygenase-containing bacteria. Environ. Sci. Technol. 2007, 41, 7330-7336.

(16) Notomista, E.; Lahm, A.; Di Donato, A.; Tramontano, A. Evolution of bacterial and archaeal multicomponent monooxygenases. J. Mol. Evol. 2003, 56, 435-445.

(17) Coleman, N. V.; Bui, N. B.; Holmes, A. J. Soluble di-iron monooxygenase gene diversity in soils, sediments and ethene enrichments. Environ. Microbiol. 2006, 8, 1228-1239.

(18) Sales, C. M.; Mahendra, S.; Grostern, A.; Parales, R. E.; Goodwin, L. A.; Woyke, T.; Nolan, M.; Lapidus, A.; Chertkov, O.; Ovchinnikova, G.; et al. Genome sequence of the 1,4-dioxanedegrading Pseudonocardia dioxanivorans strain CB1190. J. Bacteriol. 2011, 193, 4549-4550.

(19) Grostern, A.; Sales, C. M.; Zhuang, W.-Q.; Erbilgin, O.; AlvarezCohen, L. Glyoxylate metabolism is a key feature of the metabolic degradation of 1,4-dioxane by Pseudonocardia dioxanivorans strain CB1190. Appl. Environ. Microbiol. 2012, 78, 3298-3308.

(20) Sales, C. M.; Grostern, A.; Parales, J. V.; Parales, R. E.; AlvarezCohen, L. Oxidation of the cyclic ethers 1,4-dioxane and tetrahydrofuran by a monooxygenase in two Pseudonocardia species. Appl. Environ. Microbiol. 2013, 79, 7702-7708.

(21) Masuda, H.; McClay, K.; Steffan, R. J.; Zylstra, G. J. Biodegradation of tetrahydrofuran and 1,4-dioxane by soluble diiron monooxygenase in Pseudonocardia sp. strain ENV478. J. Mol. Microbiol. Biotechnol. 2012, 22, 312-316.

(22) Thiemer, B.; Andreesen, J. R.; Schräder, T. Cloning and characterization of a gene cluster involved in tetrahydrofuran degradation in Pseudonocardia sp. strain K1. Arch. Microbiol. 2003, 179, 266-277.

(23) Yao, Y.; Lv, Z.; Min, H.; Lv, Z.; Jiao, H. Isolation, identification and characterization of a novel Rhodococcus sp. strain in biodegradation of tetrahydrofuran and its medium optimization using sequential statistics-based experimental designs. Bioresour. Technol. 2009, 100, 2762-2769.

(24) Li, M.; Mathieu, J.; Yang, Y.; Fiorenza, S.; Deng, Y.; He, Z.; Zhou, J.; Alvarez, P. J. Widespread distribution of soluble di-iron monooxygenase (SDIMO) genes in arctic groundwater impacted by 1 , 4-dioxane. Environ. Sci. Technol. 2013, 47, 9950-9958.

(25) Li, M.; Mathieu, J.; Liu, Y.; Van Orden, E. T.; Yang, Y.; Fiorenza, S.; Alvarez, P. J. The abundance of tetrahydrofuran/dioxane monooxygenase genes $(\operatorname{thm} A / d x m A)$ and 1,4-dioxane degradation activity are significantly correlated at various impacted aquifers. Environ. Sci. Technol. Lett. 2014, 1, 122-127. 
(26) He, Y.; Wei, K.; Si, K.; Mathieu, J.; Li, M.; Alvarez, P. J. Wholegenome sequence of the 1,4-dioxane-degrading bacterium Mycobacterium dioxanotrophicus PH-06. Genome Announc. 2017, 5, e00625-17.

(27) Li, M.; Fiorenza, S.; Chatham, J. R.; Mahendra, S.; Alvarez, P. J. 1,4-Dioxane biodegradation at low temperatures in Arctic groundwater samples. Water Res. 2010, 44, 2894-2900.

(28) Magoc, T.; Wood, D.; Salzberg, S. L. EDGE-pro: estimated degree of gene expression in prokaryotic genomes. Evol. Bioinf. Online 2013, 9, 127.

(29) Soares-Castro, P.; Santos, P. M. Deciphering the genome repertoire of Pseudomonas sp. M1 toward $\beta$-myrcene biotransformation. Genome Biol. Evol. 2014, 7, 1-17.

(30) Neupane, S.; Finlay, R. D.; Alström, S.; Elfstrand, M.; Högberg, N. Transcriptional responses of the bacterial antagonist Serratia plymuthica to the fungal phytopathogen Rhizoctonia solani. Environ. Microbiol. Rep. 2015, 7, 123-127.

(31) Yang, Y.; Zhu, H.; Colvin, V. L.; Alvarez, P. J. Cellular and transcriptional response of Pseudomonas stutzeri to quantum dots under aerobic and denitrifying conditions. Environ. Sci. Technol. 2011, 45, 4988-4994.

(32) Li, M.; Conlon, P.; Fiorenza, S.; Vitale, R. J.; Alvarez, P. J. Rapid analysis of 1,4-dioxane in groundwater by frozen micro-extraction with gas chromatography/mass spectrometry. Groundwater Monit. Rem. 2011, 31, 70-76.

(33) Fernández-Artigas, P.; Guerra-Hernandez, E.; García-Villanova, B. Changes in sugar profile during infant cereal manufacture. Food Chem. 2001, 74, 499-505.

(34) Wittmann, G.; Van Langenhove, H.; Dewulf, J. Determination of acetic acid in aqueous samples, by water-phase derivatisation, solidphase microextraction and gas chromatography. J. Chromatogr. A 2000, 874, 225-234.

(35) Prior, S.; Dalton, H. Acetylene as a suicide substrate and active site probe for methane monooxygenase from Methylococcus capsulatus (Bath). FEMS Microbiol. Lett. 1985, 29, 105-109.

(36) Coleman, N. V.; Yau, S.; Wilson, N. L.; Nolan, L. M.; Migocki, M. D.; Ly, M. a.; Crossett, B.; Holmes, A. J. Untangling the multiple monooxygenases of Mycobacterium chubuense strain NBB4, a versatile hydrocarbon degrader. Environ. Microbiol. Rep. 2011, 3, 297-307.

(37) Auffret, M. D.; Yergeau, E.; Labbé, D.; Fayolle-Guichard, F.; Greer, C. W. Importance of Rhodococcus strains in a bacterial consortium degrading a mixture of hydrocarbons, gasoline, and diesel oil additives revealed by metatranscriptomic analysis. Appl. Microbiol. Biotechnol. 2015, 99, 2419-2430.

(38) Masuda, H.; McClay, K.; Steffan, R.; Zylstra, G. Characterization of three propane-inducible oxygenases in Mycobacterium sp. strain ENV421. Lett. Appl. Microbiol. 2012, 55, 175-181.

(39) Gilch, S.; Meyer, O.; Schmidt, I. A soluble form of ammonia monooxygenase in Nitrosomonas europaea. Biol. Chem. 2009, 390, $863-873$.

(40) Sheng, D.; Ballou, D. P.; Massey, V. Mechanistic studies of cyclohexanone monooxygenase: chemical properties of intermediates involved in catalysis. Biochemistry 2001, 40, 11156-11167.

(41) Li, M.; Liu, Y.; He, Y.; Mathieu, J.; Hatton, J.; DiGuiseppi, W.; Alvarez, P. J. Hindrance of 1,4-dioxane biodegradation in microcosms biostimulated with inducing or non-inducing auxiliary substrates. Water Res. 2017, 112, 217-225.

(42) Mitchell, K. H.; Studts, J. M.; Fox, B. G. Combined participation of hydroxylase active site residues and effector protein binding in a para to ortho modulation of toluene 4-monooxygenase regiospecificity. Biochemistry 2002, 41, 3176-3188. 